\title{
Alain Atangana, Damase Khasa, Scott Chang and Ann Degrande: Tropical agroforestry
}

\author{
Springer, 2014, ISBN 978-94-007-7722-4, DOI 10.1007/978-94-007-7723-1
}

\author{
P. K. R. Nair
}

Received: 19 December 2013/Accepted: 21 December 2013/Published online: 31 December 2013

(C) Springer Science+Business Media Dordrecht 2013

Current and comprehensive textbooks that portray the latest developments in a subject are the key to successful transfer of knowledge in the subject. In the field of agroforestry, we have witnessed a proliferation of publications during the past two decades, consisting of peer-reviewed articles in a number of world's leading scientific and thematic journals, an "Advances in Agroforestry" book series with an average of a-book-a-year for the past 10 years, and numerous other publications. In spite of this impressive record, there has been no recent publication that could be claimed as a textbook of agroforestry. The authors of this book need to be complimented for taking the bold initiative of correcting this deficiency partly by preparing a textbook of Tropical Agroforestry.

The 21 chapters of the 380-page book are organized into five major thematic sections (Parts I-V) related to tropical agroforestry. The first four present the tropical biomes and the traditional agroforestry and other land use systems, the benefits and services of agroforestry, research methods, and economic and social considerations. Finally, an outlook on agroforestry comprising an amalgam of some "trendy" issues as they relate to agroforestry is presented in Part V. Each chapter has its own bibliography making it a stand-alone piece.
The subject index with an estimated total of 500 entries points to the diversity and comprehensiveness of the topics covered in the book.

Preparing a textbook in a rapidly developing field is, indeed, a daunting task. The authors have to access, evaluate, and synthesize the mind-boggling array of ever-increasing literature; integrate new knowledge with existing information; and present the current status of the subject matter in a concise, balanced, and non-controversial form and simple language that is understandable to both the teacher and the taught. That is what the authors have accomplished in this book.

A detailed review of the book is not intended here. Because of the enormity and complexity of the task, no textbook can be claimed as complete and flawless; and, given the fast rate at which knowledge accumulates, textbooks in applied fields like agroforestry will inevitably have rather short life-spans. By referring to this as the first edition of the book (Preface), the authors seem to be aware of some such shortcomings. The reviewer encourages the readers to bring any such issues to the authors' attention so they could be addressed in later editions. Undoubtedly, the book is an outstanding contribution to the development of agroforestry and the reviewer once again congratulate the authors on this significant achievement. 